\title{
Evaluation of modifiable risk factors for peritoneal dialysis-related peritonitis: a single-center retrospective cohort study
}

Shigeki Kojima*, Shohei Yamada, Rie Fujishima, Kenichiro Koitabashi, Yugo Shibagaki and Tsutomu Sakurada

\begin{abstract}
Background: Peritoneal dialysis (PD)-related peritonitis risk factors can be categorized as modifiable and uncorrectable. We aimed to identify modifiable risk factors for PD-related peritonitis in our facility to prevent PD-related peritonitis and continue quality improvement.
\end{abstract}

Methods: This retrospective, observational study included 90 patients who started receiving PD after 2008 and who were continued for over 1 year. Twenty-three patients experienced 40 episodes of peritonitis. Several clinical factors identified at peritonitis onset among patients with a peritonitis history were compared with those identified 1 year after PD initiation among patients without a peritonitis history, and a multivariate analysis was performed. Several serum parameter levels were evaluated as time-average concentrations (TACs; from PD initiation to 1 month before peritonitis onset or to 1 year later). The clinical factors to be investigated were selected based on previous studies.

Results: There were no significant between-group differences in baseline characteristics regarding uncorrectable factors and TAC values for serum parameters. Use of exchange devices was significantly higher $(95.7 \%$ vs $71.6 \%$; $p=$ 0.054) whereas administration of renin-angiotensin-aldosterone system (RAS) blockers, calcium channel blockers (CCBs), or oral vitamin D was significantly lower (35.0\% vs $65.7 \%, p=0.002 ; 55.0 \%$ vs $74.6 \%, p=0.036$; and $55.0 \%$ vs $74.6 \%, p=$ 0.036 , respectively) in the patients with history of peritonitis, although we did not find a factor independently associated with peritonitis in multivariable logistic regression.

Conclusions: Although hypokalemia, hypoalbuminemia, and exchange device use which are considered as risk factors did not affect peritonitis, administration of RAS blockers, CCBs, and oral vitamin D is significantly larger in patients without peritonitis.

Keywords: Hypoalbuminemia, Hypokalemia, Modifiable risk factors, Peritoneal dialysis-related peritonitis, Reninangiotensin-aldosterone system blocker, Calcium channel blocker, Oral vitamin D

\section{Background}

Because of their possibility of shortening the treatment period of peritoneal dialysis (PD), PD-related infections such as peritonitis, exit-site infection, and tunnel infection are important complications among patients on PD.

\footnotetext{
* Correspondence: s2kojima@marianna-u.ac.jp

Division of Nephrology and Hypertension, Department of Internal Medicine, St. Marianna University School of Medicine, 2-16-1 Sugao, Miyamae-ku, Kawasaki, Kanagawa 216-8511, Japan
}

Furthermore, patients with recurrent peritonitis episodes have a worse prognosis [1].

Therefore, prevention of PD-related peritonitis can improve patient survival. It is known that PD-related peritonitis risk factors can be divided into modifiable and uncorrectable. Factors such as malnutrition, overweight, smoking, immunosuppression, no use of oral active vitamin D, psychosocial factors, low socioeconomic status, PD performed against patient's choice, hypoalbuminemia,

(c) The Author(s). 2021 Open Access This article is licensed under a Creative Commons Attribution 4.0 International License, which permits use, sharing, adaptation, distribution and reproduction in any medium or format, as long as you give appropriate credit to the original author(s) and the source, provide a link to the Creative Commons licence, and indicate if changes were made. The images or other third party material in this article are included in the article's Creative Commons licence, unless indicated otherwise in a credit line to the material. If material is not included in the article's Creative Commons licence and your intended use is not permitted by statutory regulation or exceeds the permitted use, you will need to obtain permission directly from the copyright holder. To view a copy of this licence, visit http://creativecommons.org/licenses/by/4.0/ The Creative Commons Public Domain Dedication waiver (http://creativecommons.org/publicdomain/zero/1.0/) applies to the data made available in this article, unless otherwise stated in a credit line to the data. 
hypokalemia, indoor pet breeding, and patient training [2, 3] have been reported to be modifiable risk factors. And active interventions to reduce modifiable risk factors may improve patient outcomes.

The aim of this study was to identify modifiable risk factors for peritonitis to raise the quality of treatment in our facility.

\section{Methods}

This retrospective, single-center, cohort study was approved by the Institutional Review Board of the St. Marianna University School of Medicine (No. 4568). The study adhered to the principles of the Helsinki Declaration. In addition, patients were given the opportunity to opt out of the study via the hospital website. The study participants included PD patients who started receiving PD between January 2008 and September 2018 and continued it for more than 1 year at the St. Marianna University School of Medicine Hospital. Although 109 patients started PD during the period, this study excluded patients who withdrew from PD in less than a year to calculate time-average concentrations (TACs; details will be described later). We compared patient's uncorrectable and several clinical factors including modifiable risk factors between patients with and without the history of PD-related peritonitis. In addition to the items listed in the introduction, modifiable risk factors included the use of laxatives [4], assisted PD [5], use of exchange devices [6], living conditions, and occupational status. Also, other clinical factors such as performance status (PS) [7] at PD initiation and use of commonly used medications for the treatment of frequent complications were examined.

The categorical variables identified at the onset of peritonitis among patients with peritonitis and those identified at 1 year after the initiation of PD which is considered to be stable period among patients without peritonitis were evaluated. Serologic tests associated with nutritional status, potassium metabolism, and chronic kidney disease-mineral and bone disorder (CKD-MBD) such as serum albumin, potassium, magnesium, corrected calcium, inorganic phosphorus, and intact parathyroid hormone $(\mathrm{PTH})$ levels were evaluated as TACs. TAC was defined from 1 month after PD initiation to 1 month before peritonitis onset for patients with peritonitis to exclude the effect of peritonitis and from 1 month after PD initiation to 1 year later for patients without peritonitis (Fig. 1).

\section{Statistical analysis}

Data are expressed as median [quartile] or mean \pm standard deviation according to data distribution. For comparisons of categorical variables, Pearson's chisquare test and Fisher's exact test were used. For determining correlations between continuous variables, Student's t-test and Mann-Whitney $U$ test were used. In addition, for multivariate analysis, logistic regression analysis was used. A p-value of $<0.05$ was considered to be significant. All statistical analyses were performed using the JMP pro 13 software (SAS Institute Japan Co, Ltd. Tokyo, Japan).

\section{Results}

We analyzed 90 PD patients. The characteristics and clinical factors including modifiable risk factors of patients with and without the history of PD-related peritonitis are shown in Table 1. There was no significant difference in uncorrectable characteristics between groups. PS at PD initiation was better in the group without peritonitis (rate of PS 0 was 69.6 vs $89.6 \%$; $\mathrm{p}=$ 0.001). Renin-angiotensin-aldosterone system (RAS) blockers, calcium channel blockers (CCBs), and oral vitamin $\mathrm{D}$ use were significantly lower and psychiatric disorder, assisted PD, and exchange device use prevalences were significantly higher in the peritonitis group than in the group without peritonitis. The breakdown of psychiatric disorders was 3 patients in dementia and 1 patient in developmental disorder in peritonitis group and 1 patient in dementia and 1 patient in developmental disorder in non-peritonitis group. However, the other examined factors including serologic test were not significantly different between the two groups.

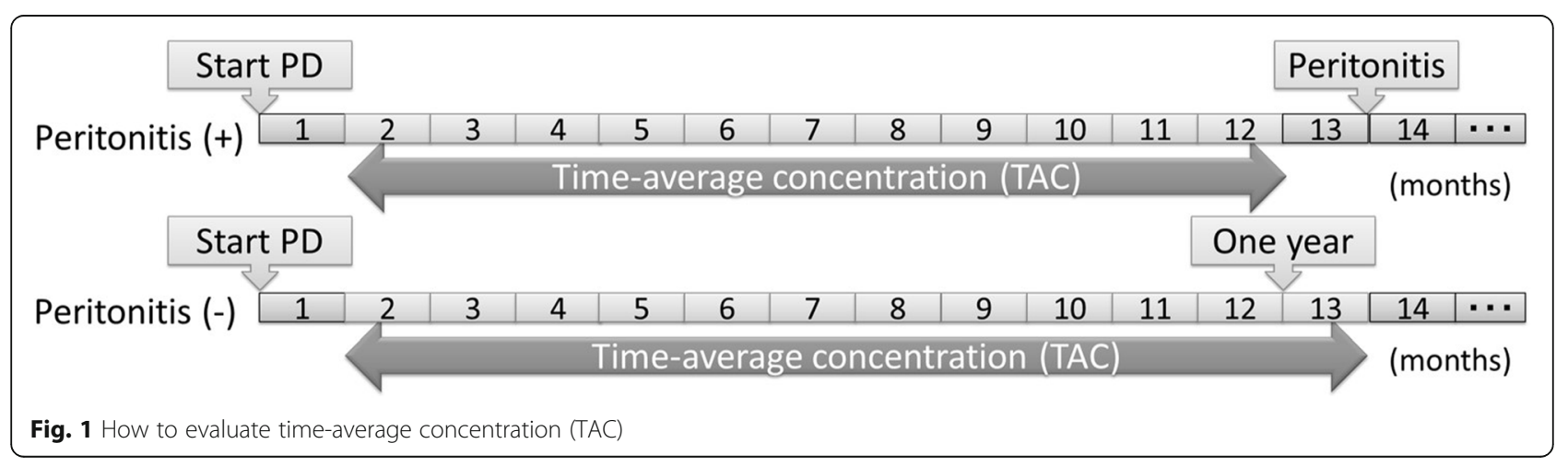


Table 1 Patient characteristics and clinical factors of patients with or without the history of peritonitis

\begin{tabular}{|c|c|c|c|}
\hline & Patients with peritonitis $(n=23)$ & Patients without peritonitis $(n=67)$ & $p$-value \\
\hline Sex (male, \%) & 60.9 & 58.0 & 0.921 \\
\hline Age at PD initiation (median, years) & $64[54-80]$ & $64[52-70]$ & 0.426 \\
\hline \multirow[t]{5}{*}{ Performance status at PD initiation (0-4) (n) } & $0(16)$ & $0(60)$ & \multirow[t]{5}{*}{ N/A } \\
\hline & $1(5)$ & $1(7)$ & \\
\hline & $2(1)$ & $2(0)$ & \\
\hline & $3(1)$ & $3(0)$ & \\
\hline & $4(0)$ & $4(0)$ & \\
\hline Diabetes* (\%) & 43.5 & 53.6 & 0.331 \\
\hline Hypertension (\%) & 29.6 & 70.4 & 0.003 \\
\hline \multicolumn{4}{|l|}{ Serologic tests time-average concentration } \\
\hline Albumin* (median, g/dL) & $3.6[2.7-3.8]$ & $3.6[3.4-3.8]$ & 0.597 \\
\hline Potassium* (median, mEq/L) & $4.2[3.8-4.7]$ & $4.1[3.9-4.4]$ & 1.000 \\
\hline Magnesium (median, mg/dL) & $2.1[1.9-2.2]$ & $2.1[1.9-2.3]$ & 0.441 \\
\hline Corrected calcium (median, mg/dL) & $9.3[8.8-9.5]$ & $9.0[8.7-9.4]$ & 0.204 \\
\hline Inorganic phosphorus (median, mg/dL) & $5.1[4.6-5.9]$ & $5.0[4.7-5.3]$ & 0.224 \\
\hline Intact PTH (median, pg/mL) & 288 [201-369] & $253[163-350]$ & 0.378 \\
\hline \multicolumn{4}{|l|}{ Use of medications } \\
\hline RAS blocker (\%) & 35.0 & 65.7 & 0.002 \\
\hline Calcium channel blocker (\%) & 55.0 & 74.6 & 0.036 \\
\hline Diuretic (\%) & 80.0 & 88.1 & 0.258 \\
\hline Oral vitamin $D^{*}(\%)$ & 55.0 & 74.6 & 0.036 \\
\hline Dose of oral vitamin $D(\mu \mathrm{g} /$ day $)$ & $0.49 \pm 0.21$ & $0.38 \pm 0.20$ & 0.011 \\
\hline Vitamin D started with SHPTH (\%) & 100.0 & 89.6 & 0.035 \\
\hline Phosphate binder (\%) & 77.5 & 88.1 & 0.148 \\
\hline Precipitated calcium carbonate (\%) & 55.0 & 73.1 & 0.055 \\
\hline Non-calcium-containing phosphate binder (\%) & 50.0 & 50.8 & 0.941 \\
\hline Calcimimetics (\%) & 17.5 & 16.4 & 0.885 \\
\hline Laxative* (\%) & 15.0 & 25.4 & 0.206 \\
\hline Erythropoiesis-stimulating agent (\%) & 95.0 & 89.6 & 0.326 \\
\hline Immunosuppressant* (\%) & 2.5 & 6.0 & 0.411 \\
\hline \multicolumn{4}{|l|}{ Other factors } \\
\hline PD against patient's choice* $(\%)$ & 4.2 & 4.5 & 0.446 \\
\hline Smoking history* (\%) & 34.8 & 49.3 & 0.229 \\
\hline Indoor pet breeding* (\%) & 17.4 & 16.4 & 0.914 \\
\hline Psychiatric disorder* (\%) & 17.4 & 3.0 & 0.017 \\
\hline Public assistance* (\%) & 4.3 & 3.0 & 0.753 \\
\hline Assisted PD (\%) & 17.4 & 3.0 & 0.017 \\
\hline Use of exchange devise (\%)* & 95.7 & 71.6 & 0.054 \\
\hline Living environment (apartment, \%)* & 43.5 & 49.3 & 0.632 \\
\hline Job (\%)* & 30.4 & 46.3 & 0.185 \\
\hline
\end{tabular}

$P D$ peritoneal dialysis, $P T H$ parathyroid hormone, SHPTH secondary hyperparathyroidism, RAS renin-angiotensin-aldosterone system Modifiable risk factors of peritonitis reported in previous studies are marked with asterisks 
Variables with a p-value $<0.05$ according to a univariate analysis were included in the multivariate analysis. However, we did not find a factor independently associated with peritonitis (Table 2).

There were a total of 40 episodes of peritonitis in 23 patients (Table 3). The median incidence time for the first peritonitis episode was 14 (8-31) months after PD initiation. Of the 40 dialysate peritonitis cultures examined, gram-positive cocci (GPC) were found in 14 and gram-negative bacilli (GNB) in 13, and the remaining 13 were culture-negative $(\mathrm{CN})$. Furthermore, 1 case was GPC and 2 cases were CNB in the dialysate peritonitis cultures of patients without exchange devices, and also, 13 cases were GPC, 11 cases were GNB, and 13 cases were $\mathrm{CN}$ in those of the patients using exchange devices. Among the 23 patients with peritonitis, 11 patients were repeaters of peritonitis. The breakdown of repeaters according to definition [8], 5 cases were "relapse," 1 case was "repeat," and 5 cases were the others. And among dialysate peritonitis cultures of relapse cases, 2 cases were GPC, 2 cases were GNB, and 1 case was $\mathrm{CN}$. The characteristics and clinical factors for patients with single episode of peritonitis and repeaters are compared in Table 3; no significant difference was found between the two groups. Of the 40 peritonitis episodes, 10 resulted in PD withdrawal (GPC 2 episodes, GNB 6 episodes, CN 2 episodes).

\section{Discussion}

The present study identified several clinical factors that were significantly more common in patients with peritonitis than in those without it. The following are discussion, respectively, for each factor.

Hypoalbuminemia is a well-known risk factor for peritonitis because serum albumin is an indicator of nutritional status $[9,10]$. However, our results showed that hypoalbuminemia was not a risk factor for peritonitis among our cohort. Some studies have reported data similar to ours and have shown no relationship between serum albumin levels and peritonitis risk [11, 12], suggesting that hypoalbuminemia, instead of being a risk factor, is a result of the inflammatory response in patients with peritonitis.

Table 2 Multivariable logistic regression of variables with significant change according to the univariate analysis

\begin{tabular}{llll}
\hline Clinical factors & Odds ratio & $\mathbf{9 5 \% ~ C l}$ & $\boldsymbol{p}$-value \\
\hline RAS blockers & 0.492 & $0.168-1.439$ & 0.195 \\
Calcium channel blockers & 1.043 & $0.187-5.818$ & 0.962 \\
Oral vitamin D & 0.512 & $0.213-1.232$ & 0.135 \\
Hypertension & 0.425 & $0.053-3.412$ & 0.421 \\
\hline
\end{tabular}

Cl confidence interval, RAS renin-angiotensin-aldosterone system
Hypokalemia has been linked to peritonitis due to decreased bowel peristalsis, which may result in intestinal bacterial overgrowth [13]. However, the TACs for potassium levels were not significantly different between patients with and without peritonitis. Although the incidence of peritonitis has been reported to increase more than 3-fold at when potassium levels fall below $3.5 \mathrm{mEq} /$ L [14], in our patients, even at peritonitis onset, average serum potassium level was $3.9 \pm 0.6 \mathrm{mEq} / \mathrm{L}$, and no association between hypokalemia and peritonitis could be shown.

Administration of antihypertensive agent in particular RAS blockers and CCBs was significantly larger in the group without peritonitis. Although it may simply be due to the patient's good PS in the present study (PS 0 patients with hypertension vs PS more than 1 with hypertension; $86.9 \%$ vs $34.8 \%, \mathrm{p}<0.001$ ), there are also reports that the administration of RAS blockers and CCBs had association with or positive effect on infectious diseases. For example, in RAS blockers, it was found that angiotensin-converting enzyme 2 contributed to the regulation of amino acid transport in the intestinal epithelium and the maintenance of homeostasis of the intestinal flora, and it is considered that it may affect dysbiosis [15]. And in CCBs, Wiewel et al. reported that prior $\mathrm{CCB}$ use is associated with reduced mortality in patients following ICU admission with sepsis [16]. Although the multivariable logistic regression does not show independent association between RAS blockers and peritonitis, because of when we deal hypertension as an intermediate variable, RAS blockers were independently associated with peritonitis (OR 0.385, 95\% CI $0.157-0.943, p=0.037$ ), we would like to further investigate that relationship.

Other than CKD-MBD and normal bone development and maintenance, it has been reported that the actions of vitamin $\mathrm{D}$ are diverse, including autoimmune diseases, neurological diseases, and pregnancy. And in the PD field, oral active vitamin D therapy of $0.25 \mu \mathrm{g} /$ day or more reportedly reduces the relative risk of peritonitis $[17,18]$, and our study also showed a probable effect of vitamin $\mathrm{D}$ on peritonitis prevention. The vitamin $\mathrm{D}$ signaling pathways regulate both the innate and adaptive immunity, maintaining the associated inflammatory response within physiological limits $[19,20]$. In the critical care field, administration of calcitriol to intensive care unit hospitalized patients with sepsis increased the expression of the antibacterial peptide cathelicidin and significantly reduced mortality compared to the placebo group [21] or decreased expression of the inflammatory cytokines IL-1 and IL-6 was observed [22]. A randomized controlled clinical trial examining the effects of oral vitamin $\mathrm{D}$ supplementation on the prevention of PDrelated peritonitis is ongoing [23]. On the other hand, 
Table 3 Patient characteristics and clinical factors of patients with single history or repeated of peritonitis

\begin{tabular}{|c|c|c|c|}
\hline & Single history $(n=12)$ & Repeaters $(n=11)$ & $p$-value \\
\hline Sex (male, \%) & 50 & 72.7 & 0.265 \\
\hline Age at PD initiation (median, years) & $64[63-77]$ & $59[53-84]$ & 0.423 \\
\hline \multirow[t]{5}{*}{ Performance status at PD initiation (0-4) (n) } & $0(9)$ & $0(7)$ & N/A \\
\hline & $1(2)$ & $1(3)$ & \\
\hline & $2(1)$ & $2(0)$ & \\
\hline & $3(0)$ & $3(1)$ & \\
\hline & $4(0)$ & $4(0)$ & \\
\hline Diabetes* (\%) & 58.3 & 27.3 & 0.133 \\
\hline Hypertension (\%) & 22.5 & 37.5 & 0.205 \\
\hline \multicolumn{4}{|l|}{ Serologic tests time average concentration } \\
\hline Albumin* (median, g/dL) & $3.6[3.4-3.8]$ & $3.6[3.0-3.9]$ & 0.594 \\
\hline Potassium* (median, mEq/L) & $4.3[3.9-4.8]$ & $4.1[3.7-4.4]$ & 0.346 \\
\hline Magnesium (median, mg/dL) & $2.1[2.0-2.3]$ & $2.1[1.8-2.2]$ & 0.451 \\
\hline Corrected calcium (median, mg/dL) & $9.3[8.8-9.4]$ & $9.2[8.8-9.5]$ & 0.974 \\
\hline Inorganic phosphorus (median, mg/dL) & $4.9[4.4-5.2]$ & $5.1[4.7-6.0]$ & 0.281 \\
\hline Intact PTH (median, pg/mL) & $290[171-431]$ & $288[215-343]$ & 0.985 \\
\hline \multicolumn{4}{|l|}{ Use of medications } \\
\hline RAS blocker (\%) & 41.7 & 35.7 & 0.722 \\
\hline Calcium channel blocker (\%) & 75.0 & 46.4 & 0.096 \\
\hline Diuretic (\%) & 91.7 & 75.0 & 0.227 \\
\hline Oral vitamin $D^{*}(\%)$ & 58.3 & 53.6 & 0.782 \\
\hline Dose of oral vitamin $D$ ( $\mu \mathrm{g} /$ day) & $0.35 \pm 0.31$ & $0.25 \pm 0.28$ & 0.443 \\
\hline Vitamin D started with SHPTH (\%) & 66.7 & 53.6 & 0.563 \\
\hline Phosphate binder (\%) & 83.3 & 75.0 & 0.443 \\
\hline Precipitated calcium carbonate (\%) & 50.0 & 53.6 & 0.836 \\
\hline Non-calcium-containing phosphate binder (\%) & 50.0 & 50.0 & 1.000 \\
\hline Calcimimetics (\%) & 0 & 25.0 & 0.057 \\
\hline Laxative* (\%) & 16.7 & 14.3 & 0.847 \\
\hline Erythropoiesis-stimulating agent (\%) & 91.7 & 96.4 & 0.527 \\
\hline Immunosuppressant ${ }^{*}(\%)$ & 8.3 & 0 & 0.122 \\
\hline \multicolumn{4}{|l|}{ Other factors } \\
\hline PD against patient's choice* (\%) & 8.3 & 9.1 & 0.949 \\
\hline Smoking history* (\%) & 41.7 & 27.3 & 0.469 \\
\hline Indoor pet breeding* $(\%)$ & 8.3 & 27.3 & 0.231 \\
\hline Psychiatric disorder* (\%) & 8.3 & 27.3 & 0.231 \\
\hline Public assistance* (\%) & 0 & 9.1 & 0.286 \\
\hline Assisted PD (\%) & 8.3 & 27.3 & 0.231 \\
\hline Use of exchange devise (\%)* & 91.7 & 90.9 & 0.949 \\
\hline Living environment (apartment, \%)* & 41.7 & 45.5 & 0.855 \\
\hline Job $(\%)^{*}$ & 25.0 & 36.4 & 0.554 \\
\hline
\end{tabular}

$P D$ peritoneal dialysis, $P T H$ parathyroid hormone, SHPTH secondary hyperparathyroidism, RAS renin-angiotensin-aldosterone system Modifiable risk factors of peritonitis reported in previous studies are marked with asterisks 
none of the serological laboratory findings associated with CKD-MBD showed a significant difference between the two groups.

Depression has been reported to be the leading psychiatric disorder associated with peritonitis, but cognitive dysfunction affected the majority of patients in this study. Immediate memory dysfunction, rather than general cognitive impairment, can predict a higher risk of PD-related peritonitis [24]. Therefore, we must keep in mind that regular assessments of a patient's cognitive function may help prevent peritonitis.

Finally, there are few reports that show effectiveness of ultraviolet or heated plate germicidal exchange devices $[25,26]$, and contrary to expectations, patients who used exchange devices exhibited high risk of peritonitis in our study, likely because the procedure was more independent in patients not using exchange devices. On the other hand, about half of the exchange device users have peritonitis caused by GNB, and the fact that even if the exchange device is used, this rate of peritonitis develops suggests the importance of preventing endogenous peritonitis.

The primary limitations of our study include the relatively small number of patients and the retrospective cohort design. Thus, the multivariate analysis we performed in the present study was insufficient to show the relationship between PDrelated peritonitis and some medicines. Further investigations including more patients and using prospective, long-term observation methods are necessary to support our conclusions.

\section{Conclusions}

We identified several modifiable risk factors associated with PD-related peritonitis that can improve the quality of treatment in our facility. In particular, administration of RAS blockers, CCBs, and oral vitamin D is significantly larger in patients without peritonitis, whereas serum albumin or potassium levels and exchange device use did not appear to affect peritonitis risk.

\section{Abbreviations \\ PD: Peritoneal dialysis; PTH: Parathyroid hormone; CKD-MBD: Chronic kidney disease-mineral and bone disorder; TAC: Time-average concentrations; \\ RAS: Renin-angiotensin-aldosterone system; CCB: Calcium channel blocker; \\ GPC: Gram-positive cocci; GNB: Gram-negative bacilli; CN: Culture-negative}

Acknowledgements

Not applicable

\section{Authors' contributions}

SY and RF helped in the data collection. TS helped to draft the manuscript.

The authors read and approved the final manuscript.

\section{Funding}

Not applicable

\section{Availability of data and materials}

The datasets used and/or analyzed during the present study are available from the corresponding author on reasonable request.

\section{Declarations}

Ethics approval and consent to participate

This study was approved by the Institutional Review Board of the St Marianna University School of Medicine, and the study adhered to the principles of the Helsinki Declaration. In addition, patients were given the opportunity to opt out of the study via the hospital website.

\section{Consent for publication}

Not applicable.

\section{Competing interests}

The authors declare that they have no competing interests.

Received: 5 September 2020 Accepted: 11 May 2021

Published online: 27 May 2021

\section{References}

1. Szeto CC, Kwan BC, Chow KM, Law MC, Pang WF, Chung KY, et al. Recurrent and relapsing peritonitis: causative organisms and response to treatment. Am J Kidney Dis. 2009;54(4):702-10. https://doi.org/10.1053/j.jajkd.2009.04. 032.

2. Cho Y, Johnson DW. Peritoneal dialysis-related peritonitis: towards improving evidence, practices, and outcomes. Am J Kidney Dis. 2014;64(2): 278-89. https://doi.org/10.1053/j.ajkd.2014.02.025.

3. Kerschbaum J, König P, Rudnicki M. Risk factors associated with peritonealdialysis-related peritonitis. Int J Nephrol. 2012;2012:483250.

4. Singharetnam W, Holley JL. Acute treatment of constipation may lead to transmural migration of bacteria resulting in gram-negative, polymicrobial, or fungal peritonitis. Perit Dial Int. 1996;16(4):423-5. https://doi.org/10.1177/ 089686089601600419 .

5. Castrale C, Evans D, Verger C, Fabre E, Aguilera D, Ryckelynck JP, et al. Peritoneal dialysis in elderly patients: report from the French Peritoneal Dialysis Registry (RDPLF). Nephrol Dial Transplant. 2010;25(1):255-62. https:// doi.org/10.1093/ndt/gfp375.

6. Dong J, Chen Y. Impact of the bag exchange procedure on risk of peritonitis. Perit Dial Int. 2010;30(4):440-7. https://doi.org/10.3747/pdi.2009. 00117.

7. Oken MM, Creech RH, Tormey DC, Horton J, Davis TE, McFadden ET, et al. Toxicity and response criteria of the Eastern Cooperative Oncology Group. Am J Clin Oncol. 1982;5(6):649-55. https://doi.org/10.1097/00000421-198212 000-00014.

8. Szeto CC, Kwan BC, Chow KM, Law MC, Pang WF, Leung CB, et al. Repeat peritonitis in peritoneal dialysis: retrospective review of 181 consecutive cases. Clin J Am Soc Nephrol. 2011;6(4):827-33. https://doi.org/10.2215/CJN. 05370610.

9. Wang Q, Bernardini J, Piraino B, Fried L. Albumin at the start of peritoneal dialysis predicts the development of peritonitis. Am J Kidney Dis. 2003;41(3): 664-9. https://doi.org/10.1053/ajkd.2003.50128.

10. Duranay M, Kanbay M, Turgut F, Altay M, Akcay A. Comparison of incidence of peritonitis between peritoneal dialysis solution types. Nephron Clin Pract. 2007;106(1):c57-60. https://doi.org/10.1159/000101485.

11. Chow KM, Szeto CC, Leung CB, Law MC, Li PK. Impact of social factors on patients on peritoneal dialysis. Nephrol Dial Transplant. 2005;20(11):2504-10. https://doi.org/10.1093/ndt/gfio61.

12. Spiegel DM, Anderson M, Campbell U, Hall K, Kelly G, McClure E, et al. Serum albumin: a marker for morbidity in peritoneal dialysis patients. Am J Kidney Dis. 1993;21 (1):26-30. https://doi.org/10.1016/S0272-6386(12)80716-5.

13. Shu KH, Chang CS, Chuang YW, Chen $\mathrm{CH}$, Cheng CH, Wu MJ, et al. Intestinal bacterial overgrowth in CAPD patients with hypokalaemia. Nephrol Dial Transplant. 2009;24:1289-92.

14. Chuang YW, Shu KH, Yu TM, Cheng CH, Chen CH. Hypokalaemia: an independent risk factor of Enterobacteriaceae peritonitis in CAPD patients. Nephrol Dial Transplant. 2009;24(5):1603-8. https://doi.org/10.1093/ndt/ gfn709.

15. Hashimoto T, Perlot T, Rehman A, Trichereau J, Ishiguro H, Paolino M, et al. ACE2 links amino acid malnutrition to microbial ecology and intestinal inflammation. Nature. 2012;487(7408):477-81. https://doi.org/10.1038/na ture11228.

16. Wiewel MA, van Vught LA, Scicluna BP, Hoogendijk AJ, Frencken JF, Zwinderman AH, et al. Prior use of calcium channel blockers is associated 
with decreased mortality in critically ill patients with sepsis: a prospective observational study. Crit Care Med. 2017;45(3):454-63. https://doi.org/10.1 097/CCM.0000000000002236.

17. Rudnicki M, Kerschbaum J, Hausdorfer J, Mayer G, König P. Risk factors for peritoneal dialysis-associated peritonitis: the role of oral active vitamin D. Perit Dial Int. 2010;30(5):541-8. https://doi.org/10.3747/pdi.2009.00108.

18. Kerschbaum J, Vychytil A, Lhotta K, Prischl FC, Wiesholzer M, MachholdFabrizii $V$, et al. Treatment with oral active vitamin D is associated with decreased risk of peritonitis and improved survival in patients on peritoneal dialysis. PLoS One. 2013;8(7):e67836. https://doi.org/10.1371/journal.pone 0067836.

19. Sterling KA, Eftekhari P, Girndt M, Kimmel PL, Raj DS. The immunoregulatory function of vitamin D: implications in chronic kidney disease. Nat Rev Nephrol. 2012;8(7):403-12. https://doi.org/10.1038/nrneph.2012.93.

20. Hewison M. Antibacterial effects of vitamin D. Nat Rev Endocrinol. 2011;7(6): 337-45. https://doi.org/10.1038/nrendo.2010.226.

21. Leaf DE, Raed A, Donnino MW, Ginde AA, Waikar SS. Randomized controlled trial of calcitriol in severe sepsis. Am J Respir Crit Care Med. 2014;190(5): 533-41. https://doi.org/10.1164/rccm.201405-09880C

22. Quraishi SA, De Pascale G, Needleman JS, Nakazawa H, Kaneki M, Bajwa EK, et al. Effect of cholecalciferol supplementation on vitamin D status and cathelicidin levels in sepsis: a randomized, placebo-controlled trial. Crit Care Med. 2015;43(9):1928-37. https://doi.org/10.1097/CCM.0000000000001148.

23. Zhang YH, Xu X, Pi HC, Yang ZK, Johnson DW, Dong J. The effects of oral vitamin $\mathrm{D}$ supplementation on the prevention of peritoneal dialysis-related peritonitis: study protocol for a randomized controlled clinical trial. Trials. 2019;20(1):657. https://doi.org/10.1186/s13063-019-3784-7.

24. Liao JL, Zhang YH, Xiong ZB, Hao L, Liu GL, Ren YP, et al. The association of cognitive impairment with peritoneal dialysis-related peritonitis. Perit Dial Int. 2019;39(3):229-35. https://doi.org/10.3747/pdi.2018.00180.

25. Ashley J, Rasooly JA, Tran I, Yost LE, Chertow GM. Effect of UV light on disinfection of peritoneal dialysis catheter connections. Perit Dial Int. 2017; 37(1):109-11. https://doi.org/10.3747/pdi.2016.00106.

26. Saito SK, Kashiwagi T, Miyahara H, lino Y, Katayama Y. A comparative study of sterility levels in continuous ambulatory peritoneal dialysis system. J Nippon Med Sch. 2010;77(6):306-11. https://doi.org/10.1272/jnms.77.306.

\section{Publisher's Note}

Springer Nature remains neutral with regard to jurisdictional claims in published maps and institutional affiliations.

Ready to submit your research? Choose BMC and benefit from:

- fast, convenient online submission

- thorough peer review by experienced researchers in your field

- rapid publication on acceptance

- support for research data, including large and complex data types

- gold Open Access which fosters wider collaboration and increased citations

- maximum visibility for your research: over $100 \mathrm{M}$ website views per year

At $\mathrm{BMC}$, research is always in progress.

Learn more biomedcentral.com/submissions 